\title{
La miseria del hogar como discurso público. Estrategias obreras en épocas de crisis. Tucumán durante los primeros años treinta
}

Maria Ullivarri*

Resumo: La crisis económica de 1929 y un golpe de Estado de orden autoritario en 1930 construyeron un escenario difícil para la lucha de los trabajadores argentinos y también para su supervivencia. En este artículo intentaremos indagar las estrategias de resistencia utilizadas por los gremios de una provincia situada al norte del país en el marco de las dificultades trazadas para la acción. El objetivo del trabajo es analizar las formas que adquirieron los discursos y las prácticas obreras de la provincia en un contexto difícil, donde, los repertorios sindicales tradicionales de demanda y protesta encontraron dificultades para ser utilizados. Palabras clave: Trabajadores. Strategia. Tucumán. Crisis. Lucha.

\section{Introducción}

Nos toca a los trabajadores unirnos y organizarnos. Ahora más que nunca es fácil nuestra unión porque nada acerca y vincula más a los seres humanos que la común desgracia y el dolor común. Hay que tratar de poner fin a esta zozobra, a esta inquietud y angustia en que nos debatimos." (Manifiesto de Sociedad de Obreros del Matadero, La Gaceta, 20/11/1932)

\footnotetext{
* Instituto Superior de Estudios Sociales (ISES), CONICET/Universidad Nacional de Tucumán. E-mail: ulliva@gmail.com
} 
Los primeros años de la década del treinta fueron angustiosos para los trabajadores argentinos. Tanto por las duras consecuencias económicas y sociales de la crisis de 1929 como por el malestar político provocado por un golpe de Estado. Encabezado por el General José Félix Uriburu - el 6 de septiembre de 1930 -, este levantamiento militar tenía por objetivo inmediato dirigir una transformación drástica de las instituciones del país para orientarlas hacia un modelo corporativo. En un escenario económico de crisis y de ilegitimidad política, su ambicioso plan estaba sustentado en mecanismos de control social respaldados por la vigencia del estado de sitio y la ley marcial. En ese contexto, la represión se transformó en un componente importante de las relaciones entre el Estado y la sociedad, y para la mayoría de las organizaciones sindicales y obreras no solo era muy difícil actuar, sino que, al mismo tiempo, veían disminuir la afluencia y la participación de sus afiliados y de los trabajadores en general.

Pero un paisaje hostil como el descripto para los primeros años de la década, oculta muy bien las formas de lucha que se entablaron en su interior. En ese sentido, en la provincia de Tucumán, al norte del país, sobre este espacio de represión y miseria, los sindicatos bosquejaron una estrategia que los grupos anarquistas denominaron "repliegue a la defensiva" (Tierra Libre 01/1935). Esta propuesta de acción no significó, empero, el abandono de la lucha sino una intensa búsqueda para adaptar el conflicto al contexto planteado, acomodar sus repertorios de acción y encontrar un nuevo, o quizás más amplio, lugar de representación para forjar solidaridades y ampliar su nómina de asociados.

En consecuencia con lo planteado, en este artículo intentaremos indagar en qué consistió el "repliegue a la defensiva" a través de la exploración de las estrategias de resistencia y de agregación utilizadas por un sector del movimiento sindical de la provincia de Tucumán en el marco de las dificultades trazadas para la acción. Asimismo, nos enfocaremos en examinar dónde abrevaron los dirigentes para construir los sentidos comunes capaces de dar impulso a la lucha y sostenerla en el marco del repliegue. El tema central del trabajo es presentar un análisis del mundo sindical de una pequeña provincia, teniendo en cuenta las formas que adquirieron 
los discursos y las estrategias obreras en un contexto difícil, donde los repertorios tradicionales de acción y de protesta encontraron dificultades para ser utilizados. En ese sentido, partimos de suponer que frente a la vulnerabilidad de la subsistencia, hombres y mujeres se enfocaron primeramente en garantizarse la vida y el sustento. Esta situación complejizó la acción y la interpelación sindical. En consecuencia, la estrategia de parte de la dirigencia obrera de la provincia de Tucumán durante los primeros años de la década estuvo centrada en tratar de darle organicidad a ese proceso de indignación, lucha por la supervivencia y defensa del hogar obrero y encuadrarlo dentro de la estructura sindical. De este modo, entendemos que la problemática y los discursos de clase se ampliaron en la provincia acompañar el conjunto de demandas sociales circulantes y el estado de ánimo colectivo.

Los escenarios conflictivos se caracterizaron por sentidos y prácticas en permanente redefinición, por eso, la propuesta intenta aprehender estos procesos de participación, acción y organización, entendiendo que la dinámica de estos "repliegues" suele ser cambiante e inestable. Tal como señala Axel Honneth (2006), no existe una sola forma de luchar, "los afligidos" combaten constantemente con unas formas de oposición que se extienden desde las confrontaciones con las autoridades a los esfuerzos desesperados por mantener la integridad de la familia y de la psique. Estos conflictos, sin embargo, no se ponen en marcha por factores macro sino que están mayormente motivados por la defraudación de ciertas "expectativas morales" que permitirían formular las propias carencias como una afrenta social, a la que la "comunidad" debería responder (HONNETH, 1997). El autor retoma de Thompson (1984) la noción de que aquello que es sentido como una situación insoportable - provisionalmente económica - más bien se mide en referencia valores compartidos que los concernidos elevan a la sociedad.

La historia del movimiento obrero argentino durante la década de 1930 fue mirada principalmente, en clave de transición al peronismo. Sin embargo, esos análisis tuvieron el mérito de abrir el debate sobre las "estrategias" obreras, las prácticas y las experiencias de los trabajadores y sus organizaciones. ${ }^{1}$ 
La miseria del hogar como discurso público. Estrategias obreras...

Algunas versiones señalaron la aparición de la política (TORRE, 2006; DOYON, 2006; DEL CAMPO, 2005). Otras pusieron el acento en la existencia de una estratégica lucha por derechos, reconocimiento de sus organizaciones e "inserción institucional" (IÑIGO CARRERA, 1998; 2004), en la búsqueda de alianzas extraobreras (PASOLINI, 2005, 2008, y BISSO, 2005) o en los vínculos con los partidos de izquierda (CAMARERO, 2002, LOBATO, 2002, DURRUTY, 1969).

No obstante, el problema de la "racionalidad" como interpretación de las formas de acción de los trabajadores, que subyace en la mayoría de estos trabajos, es que parte de una idea de estrategia que, en la mayoría de los casos, es muy homogeneizadora. En efecto, en la mayoría de las investigaciones se observa cierta reificación de las voces en disputa. El "movimiento obrero", la "dirigencia sindical", la "CGT", la "vieja guardia sindical" son actores colectivos cuyas acciones aparecen interpretadas en conjunto y, por lo tanto, desprovistas de matices. Esta situación desdibuja las luchas de sentido, los proyectos abortados, los fracasos y los repliegues que disputaron un lugar en el complejo entramado de relaciones sociales del mundo de los trabajadores. Asimismo, también oscurece las formas de lucha que no se amoldaron a "patrones estratégicos". En esa línea, Daniel James (2006) privilegiando una mirada más atenta a la subjetividad, propuso un enfoque matizado donde las decisiones "estratégicas" no opacaron los sentimientos, las emociones y las pasiones de un conjunto amplio de actores. En esta tónica poco se ha escrito sobre los trabajadores de la provincia de Tucumán y absolutamente nada sobre estos en los años treinta. ${ }^{2}$

En definitiva, las nuevas miradas sobre la historia social rescatan los espacios cotidianos de sociabilidad obrera como constructores de escenarios de resistencia a partir de la dinámica de la acción y la interacción, donde "lo racional" y "lo estratégico" adquirían un significado más difuso. (SURIANO, 1984; PALERMO, 2007) La historia del movimiento sindical es, por ello, mucho más que la historia de las organizaciones sindicales y sus estrategias globales, ya que no puede ser aislada de la acción de los sujetos, ni de sus expectativas, valores y cultura en los determinados momentos históricos. 


\section{El gobierno provisional y la contención del conflicto}

Tucumán era una provincia chica con una estructura industrial centrada principalmente en la producción azucarera y sus proveedoras. Por otro lado, los oficios más numerosos eran los de la rama de la construcción; de la alimentación y de la industria del vestido y la confección que, junto con los ferroviarios, conformaban el núcleo del movimiento obrero provincial, donde predominaban, en los primeros años de la década de 1930, corrientes anarquistas centradas en la Federación Obrera Local adherida a la Federación Obrera Regional Argentina (FORA); los comunistas que tenían una incipiente pero creciente inserción; los socialistas y una porción de sindicatos que se mantenían autónomos. Y aunque no hay datos certeros sobre la cantidad de organizaciones, sí podemos afirmar que la mayoría de los gremios se concentraban en el radio urbano a pesar de que el núcleo más numeroso de trabajadores lo centralizaba el campo y las faenas agroindustriales de la industria azucarera. ${ }^{3}$

Luego de la sanción de la ley Sáenz Peña, desde 1916 hasta 1930 Tucumán estuvo gobernada por políticos de la Unión Cívica Radical (UCR). ${ }^{4}$ Estos gobiernos manifestaron un profundo interés en vincular el Estado con los trabajadores en el marco de un proceso de apertura democrática. (BRAVO, 2009; FALCON, 1996). Sin embargo, luego del golpe de estado de 1930 no tardó en quedar claro que la preservación del orden social iba a ser el eje de las preocupaciones de la nueva administración de facto. ${ }^{5}$ En ese sentido, diez días después del golpe de Estado el gobierno provisional de la provincia invitó a los representantes de los principales sindicatos obreros tucumanos a presentar sus peticiones al Ministro de Gobierno. ${ }^{6}$ Los gremios invitados reclamaron la libertad de los trabajadores detenidos, el cumplimiento de leyes y pliegos, cuestiones vinculadas a la asistencia médica y condiciones de trabajo particulares de cada sindicato (La Gaceta, 17/09/1930).

La reunión se presentó como un posible canal de comunicación para que los trabajadores agrupados en sindicatos presenten sus demandas. No obstante, más que habilitar un espacio de diálogo, el encuentro culminó con la clara advertencia sobre la necesidad 
La miseria del hogar como discurso público. Estrategias obreras...

de ajustar sus formas de acción "a lo justo y prudente" (La Gaceta, 17/09/1930). En este contexto, ceñirse a la "prudencia" implicaba para el mundo del trabajo, y más específicamente para los trabajadores organizados en sindicatos, la obligada modificación de sus estrategias de lucha, ya que la advertencia dejaba sentado que no se toleraría ningún intento de perturbar el orden y la autoridad. ${ }^{7} \mathrm{La}$ invitación oficial intentó marcar una suerte de acuerdo tácito que confinaba la protesta "dentro del margen estricto de la ley" pero ofrecía un canal de institucionalización al problema obrero a través del Departamento Provincial de Trabajo (DPT), organismo del estado provincial destinado a resolver las controversias laborales y a vigilar el cumplimiento de las leyes.

El intento de canalizar los reclamos y conflictos a través de esa repartición estatal no significó una novedad en las prácticas de los sindicatos, que habían hecho uso de los mecanismos de conciliación, concertación y regulación laboral existentes. Sí lo fue, en cambio, que se dificultaran - o que directamente se vedaran otros canales de expresión, especialmente los vinculados al uso del espacio público o aquellos que el gobierno consideraba "extralegales." Bien lo advirtió el jefe policial, quien tiempo antes de prohibir todas las manifestaciones públicas declaró "Que vería con agrado que se pusiera la mejor buena voluntad para dar solución antes que se provocara un conflicto que la policía y el gobierno estarían en el deber de combatirlo en defensa de los bien entendidos intereses del país" (La Gaceta, 30/12/1930). Asimismo, el mensaje gubernamental explicaba "que el malestar económico nacional existe en el país como en el mundo entero y que al igual que los trabajadores de todo el mundo deben amoldarse a dicha realidad [...] El respeto del orden y la autoridad será impuesto de una manera categórica y absoluta. Los elementos que se consideren afectados por la forma en que se desenvolverá este principio de autoridad deben ser prevenidos, y las puertas del país están abiertas para su eliminación voluntaria o forzada." 8

La policía era un eje fundamental en el esquema de "orden" del gobierno y su tarea principal era la de reprimir la protesta y forzar las negociaciones o llevar a los dirigentes obreros al DPT con la exigencia de negociar y mediatizar, a través esa institución sus reclamos y evitar el conflicto o la paralización de la actividad. 
Los comunistas expresaron su repudio a estas prácticas denunciando la "ola de persecuciones", los intentos de morigerar la crisis "a costa del hambre de las masas obreras y campesinas" y la "política activísima de fascistización del movimiento sindical, uno de cuyos objetivos fundamentales es llegar a la liquidación de las huelgas y a la implementación del arbitrage (sic) obligatorio." Por su parte, los militantes anarquistas de la Federación Obrera Local Tucumana (FOLT)/FORA también salieron a dar batalla. "El capitalismo consiguió inducir a las autoridades policiales a que intervinieran en apoyo de sus planes y como resultado [...] los cuadros y calabozos están atestados de trabajadores, detenidos injustamente hasta en los propios lugares de trabajo" (Tierra Libre, 10/1930).

Pero en un contexto como el de los primeros meses de la intervención, los actos de disconformidad de trabajadores organizados terminaban en la cárcel. De este modo, las detenciones de obreros "prontuariados como ácratas" se volvieron materia frecuente durante todo el período de la intervención. ${ }^{10}$ Uno de los casos más resonantes fue el de un grupo de obreros vinculados al Sindicato de Pintores, incluido su Secretario General, quienes fueron aprehendidos mientras hacían circular panfletos contra las autoridades provisionales (La Gaceta, 09/09/1931).

De esta forma, gran parte de los intentos por "encauzar los conflictos sociales dentro de la legalidad", se insertaban en un contexto donde la policía "clausuraba locales obreros, detenía a sus militantes más activos y restringía la más elemental libertad de movimiento" (La Vanguardia, 18/07/1931). Encaminar institucionalmente la demanda significaba entonces mantenerla invisible y generar "condiciones de paz social" que permitieran reafirmar los principios de la "Revolución" y, en consecuencia, como lo advirtió el jefe policial, "no (se) adoptará ninguna providencia, mientras las partes en cuestión no se salgan de la legalidad y el orden" (El Orden, 27/02/1931). Porque "en cuanto se excedan de este límite serán reprimidas en la medida necesaria con rigor discrecional." 11 


\section{Patrones y trabajadores. El desconocimiento de lo pactado}

En los primeros años de la década de 1930 la situación económica provincial no era buena en general y la de la industria azucarera mucho menos. De este modo, al complejo escenario económico mundial se sumó la crisis de una industria subsumida en reiteradas crisis de sobreproducción. ${ }^{12}$ En una rama que funcionaba como "rueda maestra" de la economía provincial, sus dificultades tuvieron un impacto social muy violento y convirtieron al desempleo y la pobreza en algunos de los problemas más urgentes. Ante este panorama, las dificultades generales de la economía sirvieron de excusa válida a la patronal para justificar los abusos en un deliberado intento de reducir pérdidas avanzando sobre los beneficios laborales obtenidos.

Entre estas prácticas se encontraba la disminución salarial o el atraso en el pago de los jornales. Frente a la inestabilidad económica la cadena de pagos se retrasó y para aquellos que trabajaban a destajo como los albañiles, la situación fue aún más grave porque la actividad prácticamente se paralizó. Asimismo, otra de las fuentes de empleo más importantes de la provincia, el Estado, redujo su nómina de empleados con despidos masivos e intentó garantizarse fondos mediante masivas reducciones de salarios. En ese sentido, la cesantía fue una práctica extendida con la única excepción de los ferroviarios, quienes a través de sus sindicatos lograron acuerdos con las empresas por descuentos, prorrateos y retenciones con el fin de evitar la exoneración. Al finalizar los años veinte el Anuario Estadístico de la Provincia registró un total de 53.552 ocupados, cifra que en 1932 descendió abruptamente para llegar a 40.111 personas con empleo o trabajo. Por su parte, los resultados del Censo Nacional de Desocupados realizado en 1932 dieron un estimativo de 1.044 mujeres y 5.283 hombres desocupados. ${ }^{13}$

"La reacción patronal en todas partes se enseñorea", decía la FORA desde su órgano de prensa, "y a la sombra de ese movimiento empieza a echar sus garras a la garganta del proletariado" (Tierra Libre, 10/1930). Muchos patrones acusados de falta de pago solían responder que estaban esperando que los ingenios les pagasen para poder abonar a sus trabajadores. Otros alegaban que no tenían 
liquidez porque no podían competir "pagando la mano de obra que ahora pagamos, encarecida por los malos gobiernos, que han contemplado solamente esa parte del pueblo, olvidando los intereses del capital y del pequeño industrial" (La Gaceta, 17/01/1931).

Asimismo, otra de las aristas más notorias de conflicto fue el desconocimiento patronal a consensos establecidos antes del golpe, muchos de los cuales fueron considerados "caducos" por haber sido firmados durante la gestión del gobierno depuesto. Como ejemplo del desconocimiento patronal de los acuerdos y beneficios de los trabajadores podemos mencionar algunos casos como el de sastres, quienes entablaron negociaciones por el cumplimiento de pliegos firmados diez años atrás, o el de ladrilleros que demandaban el cumplimiento del pliego de $1928 .^{14}$

Pero no se avanzó solamente sobre lo acordado, sobre los derechos laborales y los salarios, sino que en el interior de los lugares de trabajo los ajustes también se hicieron sobre beneficios adquiridos. Esto fue frecuente entre los panaderos quienes solían llevar pan a sus casas y a los que paulatinamente se les fue negando ese privilegio. Algo parecido ocurrió en los mataderos donde los matarifes comenzaron a denunciar como "robo" la costumbre obrera de quedarse con los cortes de descarte. Al respecto, estos últimos trabajadores expresaron que "Por lo general ha sido costumbre antigua, de que cada uno lleve una ración de carne. Ningún matarife se ha negado a ello. Cualquiera que visite los salones verá en el piso los desperdicios que los abastecedores no lo quieren. Eso llevamos y nos agrada comer esa carne, por la costumbre [...] No hacemos otra cosa que seguir una práctica antigua y que jamás ha sido objetada" (La Gaceta, 26/02/1931).

Las "contingencias económicas" y el problema de la superproducción azucarera se habían enclavado en la provincia como ejes articuladores de un discurso que justificaba las prácticas empresarias de explotación y los incumplimientos. Sin embargo, ese avance patronal sobre los derechos obreros no se experimentó sin resistencias. A los pocos meses de la asunción del gobierno de facto y paulatinamente, en los espacios laborales comenzaron a registrarse cruzamientos de brazos, boicots, huelgas y protestas, donde se destacaban los pedidos de aumento de salarios, respeto 
La miseria del hogar como discurso público. Estrategias obreras...

de leyes y se multiplicaron los reclamos por el despido de compañeros de trabajo. Entre abril y diciembre de 1931, y a pesar de que en mayo el jefe de policía prohibió las manifestaciones en la vía pública, hubo cinco huelgas e innumerables conflictos. Sin embargo, generar un reclamo tenía sus dificultades.

Fueron principalmente los dirigentes sindicales y obreros organizados quienes comenzaron a deslegitimar las justificaciones patronales y a denunciar sus prácticas. Un afiliado a los Chauffeurs atacó a la industria azucarera señalando como falsa su justificación, "no hay superproducción hay acaparamiento" dijo, "los almacenes y depósitos se encuentran abarrotados de alimentos, mientras el pueblo se muere de hambre, por esto no hay superproducción, puesto que si estos fueran accesibles al pueblo, él los consumiría" (El Orden, 06/04/1931). Los albañiles comunistas, por su parte, indicaron que los patrones podían no respetar los acuerdos porque habían estado "amparados por el estado de sitio y la ley marcial" (La Gaceta, 03/05/1932). Mientras que la FORA llamaba desde su órgano de prensa a no dejarse arrebatar las conquistas, porque los patrones "Valiéndose de la situación de emergencia planteada por el gobierno provisional [...] disminuyen los salarios y empeoran las condiciones de trabajo [...] los atropellos del capitalismo [...] llegan hoy a un grado que no es posible seguir tolerando en silencio." Señalando que era una "provocación descarada" de los patrones y era "un deber ineludible de defender nuestras posiciones conquistadas y nuestros organismos de lucha" (Tierra Libre, 10/1930).

Pero para un conjunto amplio de trabajadores, los duros meses de la intervención de facto fueron, sin duda, conflictivos. Allí fueron acomodando sus estrategias de supervivencia y de lucha, ya que la protesta o el reclamo por las nuevas normas de trabajo traía siempre aparejado el riesgo de la cárcel o el despido. Particularmente en ese escenario la perspectiva de la represión y de la desocupación se volvió experiencia vivida sobre la base de percepciones emergentes de la crisis: la incertidumbre y la inestabilidad.

En un mercado laboral reducido para algunas ramas y caracterizado por la falta de empleo, la facilidad con que se tildaba de revoltoso a un trabajador o trabajadora, lindaba con su expulsión del mundo del trabajo. Como ejemplo podemos citar el testimonio 
de un obrero metalúrgico que relataba en esa tónica sus dificultades a la hora de encarar una protesta: "uno como obrero no puede exteriorizar sus quejas porque entonces lo dejan sin trabajo, y es más lo inhabilitan para ir a trabajar a otro taller, parece que ley del pago de los salarios puntualmente para muchos talleres de Tucumán no existe, porque si salimos de esta casa vamos a otra que es peor, como de esta forma no podemos vivir, el almacenero no nos quiere fiar, el carnicero y el panadero igual" (El Orden, 29/04/1931). Este tipo de despidos eran también frecuentes entre las mujeres, quienes estaban en una situación más desventajosa que los hombres en relación al mercado de trabajo. Un caso paradigmático en este sentido fue el despido de unas obreras de una fábrica de fideos acusadas de anarquistas por protestar por las condiciones de trabajo. Prontamente tomó intervención el DPT, siendo reincorporadas las trabajadores con el compromiso de trabajar 8 horas y de recibir el pago correspondiente. Al no cumplirse este acuerdo, las trabajadoras volvieron a protestar y fueron nuevamente despedidas.

Por tal motivo, en la mayoría de los conflictos sus cabecillas tuvieron algún cuidado en no desafiar abiertamente al poder. Los metalúrgicos de la Fundición Coulin, una de las más importantes de la provincia, que declararon una huelga en abril de 1931, lo hicieron buscando una justificación que disfrazara su "irreverencia". Esta exponía que: "si no nos pagan no tenemos otros medios que hacer una huelga forzosa ya que el Departamento de Trabajo no puede o no quiere tomar la cosa como es debido obligando al patrón que pague lo que es justo, ya que el sueldo del obrero es lo más sagrado" (El Orden, 29/04/1931).

Las organizaciones patronales, por su parte, no se quedaron a la zaga de estos discursos de "malestar" y denunciaron "continuos actos de sabotaje y un sinnúmero de atropellos contra la libertad de trabajo y contra la propiedad." A principios de 1931 y frente al aumento de estos "desmanes", comenzaron a reclamar la acción estatal. Los matarifes decían estar "cansados de sufrir la tiranía de los obreros" y recalcaban que no eran "dueños de hacer observación alguna ni de despedir a un obrero que no dé cumplimiento ni tratar de que no se robe la carne" porque eran "amenazados de muerte." (La Gaceta, 06/03/1931) Por otro lado, expresaron que deseaban 
La miseria del hogar como discurso público. Estrategias obreras...

contratar al "personal que más les convenga y no el que designe la Sociedad." (La Gaceta, 06/03/1931) y algunos, como los matarifes, solicitaron protección policial porque decían ser "víctimas y desean librarse de los trabajadores agremiados" (La Gaceta, 06/03/1931). Lo mismo hicieron los constructores luego de que un grupo de albañiles atacara con bombas de alquitrán las casas de algunos miembros del gremio patronal.

Las acciones patronales contra la sindicalización fueron frecuentes y uno de los casos más problemáticos fue el de la rama de la construcción donde los albañiles habían publicado indignados que los patrones "En su criminoso afán de llenar sus arcas [...] no tienen en cuenta el horroroso drama de indescriptibles cuadros de miserias que en los hogares de sus productores se desarrollan [...] no contentos con ultrajar lo más sagrado [...] al no cumplir el pliego de condiciones por ellos firmado (querían además) romper nuestra organización. (La Gaceta, 19/06/1930) Así también lo expresaron los obreros de los mataderos quienes explicaban a un cronista que estaban "perfectamente unidos, [...] esta manera de ser choca a los matarifes, los que quieren matarnos, desarmando nuestra institución que tantos beneficios nos reporta." (La Gaceta, 24/02/1931)

Los trabajadores, por otra parte, denunciaban la libertad que las entidades gremiales patronales tenían para manejarse. Frente a las dificultades planteadas por trámites y permisos que ellos tenían que conseguir para reunirse, los empresarios, expresaron los fideeros, "se reúnen sin previo permiso al que deben estar sometidos como ellos, para organizar las represalias contra la agremiación y que ya se han dejado sentir" (El Orden, 10/04/1931).

\section{La crisis y las formas de construir solidaridades.}

En ese escenario, tanto los discursos como las actas de asambleas que la prensa publicaba, dejan entrever que la necesidad de sumar allegados era un tema impostergable para las organizaciones obreras, especialmente porque la embestida patronal sobre los derechos obreros y el aumento de la represión generaron un retroceso en el número de allegados a los gremios. Pero en el contexto 
descripto, organizarse, plantear demandas y sostener la resistencia no fue una tarea sencilla. En efecto, podemos estimar a partir de los discursos y las demandas de acercamiento - además de los números fragmentarios de afiliación encontrados -, que el mundo sindical de la provincia no llegaba al total de trabajadores. ${ }^{15}$ Para muchos constituía un espacio ajeno a sus rutinas y sus prácticas cotidianas y, otros tantos, habían quedado fuera del mundo laboral. En ese sentido, en situaciones de marginación, miseria y desempleo, las estructuras en las cuales los individuos se referencian suelen sacudirse y generar cierta incertidumbre respecto al reconocimiento del propio rol social como proveedor o productor. En ese sentido, la familia y el trabajo son ejes identitarios fundamentales de la vida proletaria. A través del empleo los trabajadores se insertan en una red de relaciones e intercambios políticos, sociales o afectivos (GORZ, 1995, p. 26). La familia constituye una meta. Así, cuando a mediados de 1930 La Gaceta publicó una serie de reportajes a obreros bajo el título "Habla el proletariado", puso en evidencia que la principal angustia de la existencia se resumía en la imposibilidad de dar sustento a aquellos a quienes más se quería. "Formar un hogar" era, según los reportajes, una de las "misiones sociales" de los trabajadores y, como señalaron los carpinteros, era también "uno de sus inalienables derechos" (La Gaceta, 03/04/1930). Un albañil expresó que "el hogar no es privilegio de unos pocos, uno de los deberes del hombre es la constitución de la familia, justo es pues que esa familia [...] sea mantenida, alimentada, vestida, debiendo bastar porque el derecho de la igualdad así lo exige, el trabajo del jefe doméstico" (La Gaceta, 27/03/1930). Más significativo aún resulta el testimonio de otro obrero, quien destaca que en muchas oportunidades no sólo se les vedaba la mantención de una familia sino, incluso, la posibilidad de tenerla, así "hay hombres que sacrifican sus anhelos sentimentales, que renuncian a la formación del hogar porque saben que no podrían sobrellevar las cargas consiguientes [...] cómo no habrán los pobres peones de exigir siempre, ya que el amor conyugal les está vedado" (La Gaceta, 28/03/1930).

Quebrados esos lazos y esos objetivos, se hacía necesario reacondicionar las estrategias. En tal sentido, pensar y entablar luchas obreras en esas condiciones implicó conformar un público 
La miseria del hogar como discurso público. Estrategias obreras...

a quien apelar en una heterogeneidad primordial compuesta por trabajadores "conscientes" o "dignos y responsables" - como los llamó un dirigente de ATE -; pero también por aquellos desinteresados, no agremiados o desocupados. Asimismo, durante los primeros años de la década, la miseria reorientó las energías hacia la búsqueda de la supervivencia en detrimento de espacios de sociabilidad obrera más combativos (VASILACHIS, 2000). Por ello, fortalecerse y construir un lugar de representación implicó no solo seducir, interpelar y convencer, sino también marcar una línea divisoria frente a las pretensiones caritativas y "cristianizantes" de la Iglesia ${ }^{16}$, frente a aquellas acciones empresarias de fomento de la "desindicalización" o aquellas otras que, como los ingenios azucareros, influenciados por modelos de relaciones laborales paternalistas, adoptaban programas de beneficios sociales. Por otro lado, en el marco de un Estado que construía una incipiente "política social" (SURIANO; LVOVICH, 2005), tampoco debían quedarse a la zaga frente a las arraigadas esperanzas en la ayuda estatal que muchas veces fomentaba la apatía respecto a la propia agencia y dificultaban los procesos de organización.

No obstante, esta última opción fue casi inexistente durante los primeros meses de la intervención donde el objetivo fue, principalmente, contener mediante institucionalización y represión. Allí el énfasis estatal solo estuvo puesto en el aspecto legal e institucional del reclamo y dejó afuera de su umbral de tolerancia otras formas de protesta. Especialmente, el gobierno había dejado afuera de los canales permitidos las demandas más sentidas en momentos de crisis, aquellas vinculadas a la vida privada y el cotidiano de los trabajadores. Esta situación constituyó un intersticio vital para filtrar el descontento. En efecto, todo un conjunto de peticiones vinculadas con la vida diaria que no se pudieron plasmar en los ámbitos de negociación institucionalizados ni aparecieron como demandas sindicales formales, comenzaron a ponerse en locución en los discursos públicos que pudieron filtrarse: notas en los diarios, entrevistas en la prensa, cartas al director, artículos en la prensa obrera etc. Allí, envuelta en aire de tragedia, la visibilización de la miseria del hogar como consecuencia directa de incumplimientos laborales comenzó a forjarse, en esos primeros meses, como parte central de la lucha obrera en la provincia. 
El primero de estos discursos que se visibilizó, apenas un mes después de la intervención, fue un reclamo de algunos trabajadores del Ingenio Manantial. Estos dieron a conocer a través de la prensa, su reclamo por el pago de haberes adeudados y recalcaron, además, que habían concurrido a "golpear las puertas del Departamento de Trabajo en busca de que intervenga [...] sin haberlo logrado" (La Gaceta, 18/10/1930) Cumplieron "su parte del trato", pero en el Departamento nadie había entendido la inmediatez de su pedido. "Las familias obreras, señor, estamos con hambre en el Ingenio Manantial. Es menester que se nos pague lo que nosotros hemos trabajado" - dijeron.

Esta forma de reclamo, en el contexto en la que surgió fue, esencialmente, una negativa a acatar los rituales de la subordinación de una manera que ocultaba bien el contenido insolente de la demanda. ${ }^{17}$ En esa dirección, la defensa del hogar obrero comenzó a convertirse en el principal factor de protesta. Este fundamento abrevaba en un clima de época donde la desesperanza estaba generalizada. Paralelamente, ese air du temps, era profundizado con imágenes desoladoras que la prensa publicaba casi diariamente. Las crónicas, fotos y noticias publicadas remitían constantemente al vaivén de hombres caminando y mendigando. Informaban sobre gente movilizada por los pasillos oficiales, sobre grupos de cesantes protestando, mostraban la multiplicación de villas miseria y comunicaban sobre la existencia de gente que comía de la basura. También la prensa obrera participaba de esa dinámica. La crónica comunista revelaba que después de la zafra "un 70\% de la población trabajadora se encuentra sin pan" que había "más o menos cinco mil obreros golondrinas que acampan en miserables chozas hechas de hoja" y que estos "peregrinan por la ciudad pidiendo un mendrugo de pan, empezando la policía por llevarlos presos" (Mundo Obrero, 19/09/1932).

Los inicios de la década presentaron, entonces, una conjunción de elementos vinculados con la incertidumbre frente a la identidad laboral (desocupados), a la continuidad del empleo (ocupados) y la necesidad de conseguir sustento para sostener la familia. Esa situación era notoriamente visible y fue, de alguna manera, interpretada y aprehendida por la dirigencia obrera, parte de la cual buscó fomentar sentidos comunes reorientando o condimentado su tradicional discurso combativo de clase con uno más subsumido con la 
La miseria del hogar como discurso público. Estrategias obreras...

problemática cotidiana. Esto fue especialmente claro entre aquellos dirigentes con simpatías más o menos evidentes con el comunismo, partido cuyo Bureau Político hizo explícita la idea de organizar a los desocupados y exigió abordar "las reivindicaciones de los desocupados" y realizar la "denuncia de los muertos de hambre o de frío o los suicidados de desesperación." "18

Esta estrategia apareció muy clara en la idea de un mitin organizado para protestar por la desocupación, realizado el 5 de abril de 1931 por dos de los sindicatos más activos de la provincia, el Sindicato Autónomo de Obreros Albañiles y Anexos y el Sindicato Unión Chauffeurs que comenzaban a tener una impronta comunista. Desde el manifiesto de invitación se señalaba que "la lucha contra la desocupación no debía limitarse a los desocupados" y debía "ser la lucha común de todos los trabajadores unidos [porque] la lucha de los obreros desocupados es parte de la lucha contra el capitalismo" (La Gaceta, 05/04/1931). A ocupados como a desempleados afectaba por igual, ya que la experiencia de explotación era, en ambos casos, la misma, porque "la clase trabajadora que en otrora sostuvo luchas decisivas con el capitalismo, no puede permanecer impasible aceptando [que] la única libertad que existe en este país [es la] de morirse de hambre" (La Gaceta, 05/04/1931).

Hambre, desocupación y miseria consolidaron un clima para la reunión. En esa dirección, dentro de los invitados, también aparecieron las "mujeres proletarias". En este escenario - como madres - representaban el lado más oscuro de la desocupación, de la vida proletaria y de la miseria. Invitarlas junto con los niños, mostrarlas a la sociedad, ponía en juego un sistema de valores pretendidamente universal donde las ellas debían ser protegidas y visibilizaba las consecuencias más duras de la crisis. ${ }^{19} \mathrm{Y}$ aunque dentro de la retórica del desempleo, se las culpó muchas veces de ocupar puestos de trabajo perjudicando al hombre, ${ }^{20}$ acá no se las nombraba más que como madres y compañeras. En ese sentido, Mirta Lobato (2007, p. 296) destacó que cuando los trabajadores se reunían, la presencia femenina era casi inexistente, "ella solo cobraba fuerza cuando se plantea como necesidad narrativa mostrar la brutalidad del sistema capitalista." Apelando a la experiencia fuera del ámbito de la producción, las mujeres fueron presentadas como "madres proletarias" y nada se dijo sobre su condición de trabajadoras o 
como "el grupo con más alto índice de desocupación." ${ }^{21}$ El texto del manifiesto hacía un llamado a todas ellas, convocándolas a estar "a la par del obrero [...] para demostrar a los ricos que mientras ellos viven en hogares entre el lujo y la abundancia, hay un pueblo que sufre hambre, que hay madres proletarias semidesnudas, que hay niños débiles, que agonizan y mueren en los brazos de las madres proletarias en la miseria, sin atención médica y sin los remedios indispensables para su curación." (La Gaceta, 05/04/1931)

El día del mitin los discursos abordaron varios temas, pero la evocación a la miseria del hogar fue el más recurrente. El primero en hacer referencia a ello fue un albañil identificado como Pedro Gómez, quien explicó desde las tarimas que realizaban "un acto de protesta pidiendo el pan para nuestros hijos que a diario lloran por él. A nosotros, los padres, se nos despedaza el corazón al sentir esos ayes lastimosos en nuestros hogares humildes."(El Orden, 06/04/1931). El hambre del hogar obrero a consecuencia de incumplimientos laborales, desocupación o avance patronal no admitía justificaciones macroeconómicas, debido a que "se hace cada vez más insoportable [...] y en todos lados se presenta ya no como fantasma [...] sino como una realidad" (La Gaceta, 05/04/1931).

Las palabras de este orador pusieron en escena tramas cotidianas, relaciones familiares y el sufrimiento de los próximos. El orador apeló a la sensibilidad colectiva que sabía receptiva ya que el desempleo era un tema socialmente muy presente y material de crónica diaria en la prensa provincial. Pero la prédica no terminó allí, el albañil continuó explicando que "a raíz del hambre que nos azota, hemos decidido ocupar con el mayor empeño el puesto de lucha contra el capitalismo, siendo necesario sellar la unidad de todo el proletariado, como el verdadero camino que nos conducirá a un triunfo" (ElOrden, 06/04/1931). De esta forma, destacaba la desventura pero la leía en clave de explotación y manifestaba su rol de obrero "consciente". La conciencia era, en definitiva, la expresión cultural de la experiencia manifestada a través de sistemas de valores, ideas y formas institucionales. Era la conciencia el elemento fundamental que empujaba a la acción política, a la construcción de organizaciones y a la solidaridad (Thompson, 1989). Pero como señala Thompson (1989), si bien "la experiencia aparece como determinada, la conciencia de clase no", a la consciencia había que construirla o despertarla. 
El mismo orador lo planteó en estos términos: "Para conquistar el pan hay que unirse no olvidando que es nuestro deber concurrir a todos los actos de nuestras organizaciones cuidarlas y amarlas porque es el arma con que contamos nosotros para emanciparnos del yugo capitalista y terminar la vergonzosa explotación a 6 que estamos sometidos" (El Orden, 06/04/1931). En estas últimas líneas el discurso retomó la retórica tradicional del mundo obrero, señalando como "injusta la dominación de una clase sobre otra, desde que constituye una ínfima minoría que se aprovecha del esfuerzo y la producción de la extensa mayoría de los obreros que no poseen nada y viven sumidos en la miseria" (ElOrden, 06/04/1931). De esta forma, pusieron en locución los sentidos de la coacción económica que se inscribía en la relación asalariada y productiva de la vida obrera, pero que, indisociablemente, se vinculaba con todas las aristas extraproductivas del cotidiano de los trabajadores. Así, visibilizar la experiencia, verbalizar el hambre y la miseria, conformaban un acto visceral que emergía por detrás de las normas públicas del discurso obrero clásico.

Las demandas puestas en locución por los oradores, asimismo, trascendían - en términos de la lucha - la necesidad de esperar respuestas del Estado. Los discursos mostraron una desesperanza dolorosa respecto a posibles respuestas concretas y dejaron en evidencia que la mayoría de los trabajadores no tenía expectativas sobre las solicitudes, aunque si abrigaban la esperanza de sumar solidaridades.

El ostensible descreimiento en las posibles soluciones nos permite pensar que lo central en este punto fue cómo se construyó la movilización y la demanda y lo que ésta generó, más allá de los pedidos concretos y las respuestas del Estado. Salir a la calle fue un paso destacado en el proceso de "quebrar la indiferencia" y potenciar las posibilidades de fortalecer las organizaciones. En ese sentido, en un contexto como el de esos años, exponerse en el espacio público y demandar, era un acto político y también una acción de protesta que daba cuenta de los efectos más mediatos de esa experiencia de explotación por la cual se protestaba.

De esta forma, frente a la inacción estatal, y abrumados por las dificultades para sostener y alimentar a una familia, los dirigentes sindicales construyeron una estrategia de lucha para terminar 
con la explotación de clase a través de factores que atravesaban la vida de todos: la miseria y la desocupación, y apelaron a las emociones para construir la demanda e instalarla en el espacio. Asimismo, los organizadores intentaron dar respuestas para ese estado de ánimo proponiendo estrategias de lucha y soluciones posibles a través de la vinculación con las organizaciones.

El representante de los Chauffeurs lo graficó con estas palabras: "nadie es nuestra defensa, sino somos nosotros mismos, debemos comprender que la única arma son las agrupaciones obreras, y debemos fortalecernos para defender la vida de nuestros derechos" (El Orden, 06/04/1931).

Pero, la vinculación entre una problemática de clase, la identidad de clase y su institucionalización en una organización no fue un proceso mecánico, sino objeto de constante elaboración y redefinición. En este sentido, como señala Sewell (1992, p. 125), el desarrollo de la conciencia colectiva es menos una cuestión de reconocer hechos palpables que de construir redes interpretativas que den a ciertos actos una relevancia especial. Angustia, desamparo y necesidad eran palabras que revelaban la experiencia colectiva y la pérdida del acceso a algunos bienes de consumo, así como también el deterioro de sus condiciones de vida, la desocupación y las trabas a su vida familiar, comenzaron a abonar discursivamente la idea de lucha por un futuro mejor sobre la unidad y la solidaridad.

El eje puesto en la verbalización de las carencias privadas potenció las posibilidades de articular colectivamente la experiencia. La utilización de imágenes o discursos de otra índole estaban siempre mediatizados por experiencias diferenciadoras desde lo cultural, lo laboral, lo social, lo político y lo ideológico. Esto planteaba una dificultad que varios oradores abordaron. Los relatos periodísticos destacan el testimonio de un albañil de apellido Trejo quien "se ocupó con especialidad del deber que concierne a los obreros, los cuales deben desprenderse de las ideologías que los han mantenido distanciados entre sí, en procura de la unión que es el precepto básico de la fuerza." (El Orden, 06/04/1931) Mientras que la Unión Chauffeurs citó "a todos los gremios sin distinción, a responder con su cooperación en este movimiento que se hace en procura de mejor pan, más equidad y mayor justicia” (El Orden, 06/04/1931). 
La búsqueda de un camino de homogeneidad y los llamados a no incurrir en conflictos ideológicos se relacionaban con lo que se estaba poniendo en juego: la reconstrucción de un escenario sindical que, aunque modesto, había sido golpeado por la crisis y la represión. En este sentido, la unidad de clase se presentó como posibilidad de

( contención frente a la incertidumbre de la vida y como garantía para el cumplimiento de los derechos que les correspondían.

La demanda por asegurar la propia subsistencia tuvo un contenido moral, pero también, e insoslayablemente, un sentido político. En definitiva, como lo expresa Nancy Fraser (1994), los intentos de ubicar cuestiones concernientes a la domesticidad, como aquellos "ayes lastimosos" o el "corazón despedazado", fuera del debate público - personalizándolos o familiarizándolos - resulta una estrategia de los grupos dominantes. Las luchas por ubicar estos problemas en el espacio público haciendo partícipes a un conjunto mayor de personas sirven para revertir la subordinación asociada a esa situación que algunos sectores pretenden invisibilizar. Cómo hacerlo sino a través de las organizaciones, porque como afirma Pierre Bourdieu (2007), la esfera política pública no reconoce ninguno de estos esfuerzos sociales como forma relevante de conflicto social. En cambio, una especie de filtro perceptivo garantiza que sólo los problemas que ya han alcanzado el nivel organizativo de un movimiento político se tomen en serio en términos morales.

\section{Las consecuencias y los significados. Reflexiones finales}

En los primeros años de la década de 1930 se vivieron en el país las consecuencias de una crisis económica sin precedentes, el derrocamiento de un gobierno democrático y el desprestigio de las instituciones liberales y de toda la ingeniería institucional articulada en torno a la ley Sáenz Peña. Estas situaciones franquearon las vidas de todos los hombres y mujeres trabajadores/as que debieron adaptarse a los vaivenes de un régimen que, apoyado en la exclusión, recortó los márgenes de la ciudadanía y potenció las sensaciones de explotación, de desarraigo político y de injusticia social. La tensa 
articulación entre un Estado con un gobierno ilegítimo y los trabajadores se quebrantaba al compás del deterioro de las condiciones materiales y la violencia contra ellos ejercida. En ese mismo sentido, el desconocimiento patronal de lo pactado y la pérdida de beneficios, abonaban un escenario crítico. Esta particular situación que afectó profundamente el mundo del trabajo y los hogares obreros e introdujo en la dinámica del cotidiano la necesidad de construir nuevas estrategias para lidiar con la "incertidumbre de la supervivencia" (SAVAGE, 2004).

Para la dirigencia sindical se volvió urgente la exigencia de encontrar nuevas formas de acercamiento y reclutamiento. Esta estrategia se construyó sobre una disputa de relaciones de fuerza, pero fundamentalmente de sentidos y abarcó todos los aspectos y ámbitos de la vida proletaria.

Los discursos visibilizan estrategias y traducen experiencias comunes. La palabra, dice Arlette Farge (2008, p. 66), es artesana de sensaciones. Un contexto difícil, conflictos por falta de pago y despidos, reclamos por hambre y un manifiesto de invitación plagado de emotividad y descripciones dolorosas sobre desocupación, miseria y dolor construyeron un clima y acercaron a la multitud al acto. Estas imágenes expresaron un punto de partida recogiendo las sensibilidades colectivas y al mismo tiempo articularon una esperanza factible y un medio para lograrla a través de la vinculación con organizaciones obreras.

Atravesar la crisis conllevaba la búsqueda de alimentos en las ferias francas, los problemas de abastecimiento, la mendicidad, el acaparamiento, el encarecimiento de la vida y la vuelta atrás de las conquistas obtenidas con sacrificios. Este cotidiano plagado de dificultades fue interpretado como un factor de unificación a través de los sentimientos comunes y vivencias compartidas que se consolidaron discursivamente. Los discursos dejaron, además, sentada la disconformidad con el yugo capitalista y demandaron cuestiones políticas - libertad de prensa, libertad de palabra y el levantamiento del estado de sitio -, pero también dieron expresión pública a sensaciones y vivencias. La emoción del hijo llorando por pan adquirió, en este mitin, el mismo contenido político que la promesa del fin de la dominación de clase. 
Pensado entonces en términos de derechos vulnerados, pero también como estrategia discursiva, el problema de la miseria y la desocupación se constituyó como uno de los factores que les permitieron a los dirigentes obreros repensar nuevas formas de demanda y lucha. Estos trabajadores constituyeron un conjunto de representaciones por medio de las cuales se identificaban, se reproducían y se expresaban las necesidades del grupo a través de un discurso que buscaba construir solidaridades.

Los dirigentes sindicales - o aquellos a quienes la prensa registró con nombre propio- construyeron políticamente un argumento sustentado en los valores de lo justo y en expectativas familiares que los definían como grupo. Y lo hicieron a través de un doble registro en el discurso: la explicación de la privación que los aunaba como clase y la marca de un curso de acción.

En definitiva, la estrategia de la dirigencia permitió relacionar lo cotidiano con lo político, ubicando la vida privada en el mundo público y disputando el espacio - material, simbólico y discursivo - para que ese malestar sea considerado legítimo.

\section{THE HOUSEHOLD POVERTY AS PUBLIC DISCOURSE. WORKERS STRATEGIES IN TIMES OF CRISIS. TUCUMÁN DURING THE EAR- LY THIRTIES}

Abstract: The 1929 economic crisis and a military coup in 1930 built a difficult stage for the struggle of Argentine workers and also for their survival. In this article we'll investigate the resistance strategies used by the unions of province situated in the north of the country in the context of the challenges laid out for actions. This study aims to analyze the forms acquired by discourses and practices of the workers of the province in a difficult atmosphere, where traditional union repertoires of demand and protest were difficult to be used.

Keywords: Workers. Strategies. Tucumán. Crisis. Struggle.

\section{Notas}

${ }^{1}$ En ese sentido, cuando hablamos de estrategias entendemos un conjunto de comportamientos y conductas ("racionales" o no) que los actores implementaron para acumular beneficios, amortiguar pérdidas, aprovechar oportunidades, adaptarse a nuevas coyunturas o modificar sus condiciones de trabajo y de vida, es decir, para alcanzar algún objetivo específico. 


\section{Maria Ullivarri}

2 María Celia Bravo (2008) rescató la acción de los trabajadores azucareros en las huelgas agrarias y subrayó la compleja relación de estos con los cañeros en los años veinte. Florencia Correa Deza (2007) realizó estudios cuantitativos sobre salarios hasta 1927, Esteban Piliponsky (2008) abrevó en la transición hacia el peronismo, lo mismo que Oscar Pavetti (2005) y Gustavo Rubinstein (2006); mientras que Bravo y Teitelbaum (2009), se enfocan en la dinámica de las asociaciones obreras en los primeros años del siglo XX.

${ }^{3}$ La Guía Comercial de Tucumán o los censos del Departamento Nacional de Trabajo reconocen a muy pocas organizaciones. Las memorias del Departamento Provincial de Trabajo solo mencionan aquellas en cuyos conflictos intervino. En consecuencia, la gran mayoría de las organizaciones quedó al margen de las estadísticas oficiales. Pero, a través de la prensa encontramos las prácticas, las notas, los manifiestos y los discursos de un conjunto vasto de organizaciones sindicales sin registro oficial que tenían una existencia de hecho.

${ }^{4}$ La Ley Sáenz Peña, sancionada en 1912, reformó el sistema electoral del país introduciendo el voto universal masculino y obligatorio.

${ }^{5}$ Korzeniewicz (1993) recalca que los primeros meses que siguieron al golpe se especuló con la idea de promover la incorporación corporativa del trabajo organizado. Matsushita (1986) lo plantea que no constituyó una preocupación del "régimen" como lo describe Korzeniewicz, sino que fue una idea del director del Departamento Nacional de Trabajo, Eduardo Maglione. McGee (2005) y Horowitz (2004) señalan que en un principio convivieron dos tendencias al interior de la coalición gobernante. Una de ellas partidaria de resolver las disputas entre capital y trabajo mediante la conciliación y reprimir sólo a los más combativos. La otra, partidaria de la represión lisa y llana que, en definitiva, fue la que se impuso tras la renuncia de Maglione en mayo de 1931.

${ }^{6}$ Los invitados fueron Luz y Fuerza, Sociedad de Resistencia de Obreros Panaderos, Sociedad de Resistencia de Obreros Sastres, Unión Chauffeurs, Sociedad de Resistencia de Obreros Albañiles y anexos, Sindicato de Pintores, Sociedad de Resistencia de Obreros Mosaístas, Sindicato de Carpinteros, Aserradores y Anexos y Sindicato de Mozos.

${ }^{7}$ BOLETÍN DEL TRABAJO, Año 7, Buenos Aires, Octubre de 1930.

${ }^{8}$ BOLETÍN DEL TRABAJO, Año 7, Buenos Aires, Octubre de 1930.

9 "La situación de la clase obrera.... (título completo ilegible)", Documento del Partido Comunista, Junio de 1931, Legajo del PC, n. 3362, AGN, p. 1.

${ }^{10}$ Nicolás Iñigo Carrera (1994) destaca que los anarquistas fueron las principales víctimas de la policía entre 1931 y 1933. En la provincia de Tucumán hubo, según información de la prensa, un mayor número de detenciones de anarquistas respecto al total, ya que los sindicatos y dirigentes vinculados o cercanos a la FORA eran más propensos a sufrir clausuras y persecuciones. Sin embargo, la FORA tucumana destacó tiempo después en su órgano de prensa, que Tucumán 
constituyó una excepción, por lo menos en lo referente a las provincias del norte, ya que durante el período uriburista la organización, aunque con dificultades pudo mantenerse. Tierra Libre, Año 7, n. 24, Tucumán, Enero de 1935.

${ }^{11}$ BOLETÍN DEL TRABAJO, Año 7, Buenos Aires, Octubre de 1930.

12 Presa de reiteradas crisis de superproducción desde 1925, la industria azucarera llegó a 1930 con stocks acumulados sin mercado y ese año los beneficios no llegaron a cubrir los costos de producción. En los años posteriores la sobreproducción continuó dejando un remanente que agravó las pésimas condiciones económicas en las que se desarrollaba la actividad en el país, con la retracción del mercado interno y una coyuntura externa desfavorable para las exportaciones (CAMPI y KINDGARD, 2002). Entre 1931 y 1933 varios ingenios dejaron de moler.

${ }^{13}$ La Gaceta, 24/08/1932. DEPARTAMENTO NACIONAL DE TRABAJO. La desocupación en la Argentina. Buenos Aires, 1940; DEPARTAMENTO NACIONAL DEL TRABAJO. Boletín Mensual. Buenos Aires, Noviembre de 1932. ${ }^{14}$ La Gaceta, 12/03/1931.

${ }^{15}$ Los datos son dispersos y corresponden a diferentes años, pero podemos estimar que el promedio de afiliados a los sindicatos era de 40 personas, muchas de las cuales no tenían una participación activa en la institución.

${ }^{16}$ A partir de la fundación de la Acción Católica Argentina en 1931 comenzaron a tomar nuevo empuje las organizaciones obreras de base católica destinadas a "promover y defender el bienestar material y espiritual de la clase obrera" y contrarrestar "la funesta propaganda del socialismo y de la impiedad" (MARTIN, 1997. p. 59)

${ }^{17}$ Sobre las contravenciones que ponen en cuestión los sistemas de dominación, Scott, 2000. Según datos del DPT, en lo que iba del año se había conseguido que se abonara a 352 obreros que habían presentado su denuncia por falta de pago. La Gaceta, 21/11/1930.

18 "Parte dispositiva de una circular del Bureau Político Sudamericano", Sección Especial de Policía, Año 1933, Caja 45, Doc. n. 135, Fondo Agustín P. Justo, AGN; "Organizar sistemáticamente la lucha contra la desocupación” en, "La situación de la clase obrera ....(título completo ilegible)", Documento del Partido Comunista, Junio de 1931, Legajo del PC, n. 3362, AGN, p. 6.

${ }^{19}$ Daniel James (2006) expresa que el tema de la amenaza a las obreras, y la necesidad de proteger a las mujeres era un tema recurrente de la cultura popular y, en este sentido, su ubicación como principal víctima de la miseria reflotaba la necesidad de protegerlas y daba impulso a la lucha.

${ }^{20}$ Esto podía leerse en las crónicas de los diarios, como así también en las declaraciones de algunos dirigentes u organismos oficiales como la Junta Nacional para Combatir a la Desocupación. GIRBAL-BLACHA, 2003.

21 DEPARTAMENTO NACIONAL DEL TRABAJO. Investigaciones Sociales. Buenos Aires, 1940. 


\section{Referências}

AGULHON, Maurice. Historia Vagabunda, México: Instituto Mora, 1994.

BATALHA, Claudio., Identidade da Classe operária no Brasil (1880-1920): Atipicidade ou legitimidade, Revista Brasileira de Historia, São Paulo, v. 12, n 23/24, p. 111-124, sept/agos 1992.

BOURDIEU, Pierre. (Dir.). La miseria del mundo. Buenos Aires: FCE, 2007.

BRAVO, Maria Célia. Campesinos, azúcary politica: cañeros, acción corporativa y vida política en Tucumán (1895-1930). Rosario: Prohistoria, 2009.

; TEITELBAUM, Vanesa Socialistas y católicos disputando el mundo los trabajadores. Protesta, sociabilidad y cultura obrera en Tucumán (1895-1910). Entrepasados, Buenos Aires, Año XVIII, n. 35, 2009.

CORREA DEZA, Florencia. Evolución de los salarios reales de los peones azucareros de Tucumán, 1904.1927. Tesina (Licenciatura en Economía). Universidad Nacional de Tucumán, 2007.

CROSS, Cecilia. Luchas, prácticas asociativas y procesos de vinculación política en la zona metropolitana de Buenos Aires: estudio de casos en cinco organizaciones territoriales vinculadas a la FTV. Tesis (Doctorado en Ciencias Sociales). Universidad de Buenos Aires, Buenos Aires, 2007.

DEL CAMPO, Hugo. Sindicalismo y Peronismo. Los Comienzos de un Vinculo Perdurable. Buenos Aires: Siglo XXI, 2005.

DOYON, Louise. Perón y los trabajadores. Buenos Aires: Siglo XXI, 2006.

FALCÓN, Ricardo. "La relación Estado-sindicatos en la política laboral del primer gobierno de Yrigoyen”. In: Estudios Sociales, n. 10, a. VI, Santa Fe: Universidad Nacional del Litoral, $1^{\circ}$ semestre de 1996.

FARGE, Arlette, Efusión y tormento. El relato de los cuerpos. Historia del pueblo en el siglo XVIII, Buenos Aires, Katz, 2008.

FRASER, Nancy. Reconsiderando la esfera pública: una contribución a la crítica de la democracia existente". Entrepasados, n. 7, 1994.

GIRBAL-BLACHA, Noemi. "La Junta Nacional para Combatir la Desocupación. Tradición y modernización socioeconómica en la Argentina de los años treinta”, Estudios del Trabajo, n. 25, Enero-junio, 2003.

GORZ, André. Metamorfosis del trabajo. Búsqueda del sentido. Crítica de la razón económica, Madrid: Sistema, 1995.

HOGGART, Richard. As utilizações da cultura. Aspectos da classe trabalhadora como especiais referências a publicações e divertimentos, Lisboa: Presença, 1973. 
HONNETH, Axel. "Redistribución como reconocimiento: Respuesta a Nancy Fraser”. In: FRASER, N.; HONNETH, A. ¿Redistribución o reconocimiento?, Barcelona: Morata-Paideia, 2006.

- La lucha por el reconocimiento: Por una gramática moral de los conflictos sociales. Barcelona: Crítica, 1997.

IÑIGO CARRERA, Nicolás. "Formas de lucha de la clase obrera y organizaciones políticas en la Argentina de los años '30". Documento de trabajo PIMS A, Año II, n. 2, 1998.

La estrategia de la clase obrera, 1936. Buenos Aires: Madres de Plaza de Mayo, 2004.

. "La huelga general de masas de 1936: un hecho borrado en la historia de la clase obrera argentina”. In: Anuario IEHS, n. 9, Tandil, 1994.

JAMES, D.aniel Resistencia e integración. El peronismo y la clase trabajadora argentina. 1946-1976. Buenos Aires: Siglo XXI, 2006.

KORZENIEWICZ, Roberto. "Las vísperas del peronismo. Los conflictos laborales entre 1930 y 1943”. Desarrollo Económico. Buenos Aires, v. 33, n. 131, 1993.

LOBATO, Mirta., Historia de las trabajadoras en la Argentina (1869-1960). Edhasa, Buenos Aires, 2007.

LÜDTKE, Alf. "Sobre los conceptos de vida cotidiana, articulación de las necesidades y "conciencia proletaria". Historia Social, n. 10. primavera-verano, p. 41-61, 1991.

MARTIN, María Pía, “Católicos, control ideológico y cuestión obrera. El periódico La Verdad de Rosario (1930-1946). In: Estudios Sociales, Año VII, n. 12, Santa Fé, $1^{\circ}$ semestre de 1997.

MATSUSHITA, Hiroshi. Movimiento obrero argentino, 1930-1943. Hyspamérica, Buenos Aires, 1986

MCGEE DEUTSCH, Sandra. Las Derechas. La extrema derecha en la Argentina, el Brasily Chile. 1900-1939. Quilmes: Ed. UNQ, 2005.

PALERMO, Silvana. "Trabajo masculino, protesta femenina? La participación de las mujeres en la gran huelga ferroviaria de 1917', In: BRAVO, M., GIL LOZANO, F. y PITA, V. (Comp.) Historias de luchas, resistencias y representaciones. Mujeres en la Argentina, siglos XIX y XX. Tucumán: EDUNT, 2007.

PAVETTI, Oscar. Tucumán en vísperas del peronismo. Acción y difusión del catolicismo en el movimiento obrero. In: Actas de las II Jornadas Nacionales de Historia Argentina. Buenos Aires, octubre de 2005. 
PILIPONSKY, Esteban. Autonomía y peronización. El sindicalismo tucumano (1943-1946). Tesina de Licenciatura. Universidad Nacional de Tucumán, 2008.

SÁBATO, Hilda. La política en las calles. Entre el voto y la movilización. Buenos Aires, 1862-1880. Quilmes: Ed. UNQ, 2004.

SCOT'T, James. Los dominados y el arte de la resistencia. Discursos ocultos. México: Era 2000 .

SEWELL, William. Cómo se forman las clases: reflexiones críticas en torno a la teoría de E.P. Thompson sobre la formación de la clase obrera. Historia Social, n. 18, 1994.

Los artesanos, los obreros de las fábricas y la formación de la clase obrera francesa, 1789-1848. Historia Social, n. 12, 1992.

SURIANO, Juan. Los dilemas actuales de la historia de los trabajadores, In: GELMAN, Jorge (Comp.). La historia económica argentina en la encrucijada. Buenos Aires: Prometeo, 2006.

La huelga de inquilinos de 1907, In: ARMUS, D. Sectores populares y Vida Urbana, Buenos Aires: CLACSO, 1984.

; LVOVICH, Daniel, Las políticas sociales en perspectiva histórica, 1870-1952. Buenos Aires, UNGS-Prometeo, 2005.

THOMPSON, Eduard Palmer. Tradición, revuelta y conciencia de clase. Crítica: Barcelona, 1984.

- La formación de la clase obrera en Inglaterra. Crítica: Barcelona, 1989.

TORRE, Juan Carlos. La vieja guardia sindicaly Perón. Buenos Aires: Eduntref, 2006 VASILACHIS de GIALDINO, Irene. (Comp.) Pobres, pobreza y exclusión social: nuevas perspectivas epistemológicas, teóricas y metodológicas, Buenos Aires, CEILCONICET, 2000.

Recebido em 09/10/2011

Aprovado em: 21/03/2012 